\title{
Sex differences of leukocytes DNA methylation adjusted for estimated cellular proportions
}

\author{
Masatoshi Inoshita', Shusuke Numata ${ }^{1 *}$, Atsushi Tajima ${ }^{2,3}$, Makoto Kinoshita $^{1}$, Hidehiro Umehara', \\ Hidenaga Yamamori ${ }^{4,5}$, Ryota Hashimoto ${ }^{5,6}$, Issei Imoto ${ }^{2}$ and Tetsuro Ohmori ${ }^{1}$
}

\begin{abstract}
Background: DNA methylation, which is most frequently the transference of a methyl group to the 5-carbon position of the cytosine in a CpG dinucleotide, plays an important role in both normal development and diseases. To date, several genome-wide methylome studies have revealed sex-biased DNA methylation, yet no studies have investigated sex differences in DNA methylation by taking into account cellular heterogeneity. The aim of the present study was to investigate sex-biased DNA methylation on the autosomes in human blood by adjusting for estimated cellular proportions because cell-type proportions may vary by sex.

Methods: We performed a genome-wide DNA methylation profiling of the peripheral leukocytes in two sets of samples, a discovery set (49 males and 44 females) and a replication set (14 males and 10 females) using Infinium HumanMethylation450 BeadChips for 485,764 CpG dinucleotides and then examined the effect of sex on DNA methylation with a multiple linear regression analysis after adjusting for age, the estimated 6 cell-type proportions, and the covariates identified in a surrogate variable analysis.

Results: We identified differential DNA methylation between males and females at 292 autosomal CpG site loci in the discovery set (Bonferroni-adjusted $p<0.05$ ). Of these $292 \mathrm{CpG}$ sites, significant sex differences were also observed at 98 sites in the replication set $(p<0.05)$.

Conclusions: These findings provided further evidence that DNA methylation may play a role in the differentiation or maintenance of sexual dimorphisms. Our methylome mapping of the effects of sex may be useful to understanding the molecular mechanism involved in both normal development and diseases.
\end{abstract}

Keywords: Epigenetics, DNA methylation, Sex, Microarray, Leukocyte, Blood, Cell heterogeneity

\section{Background}

Sex differences have been widely observed not only in genetics and hormones but also in expression of genes and microRNA [1-4]. DNA methylation, which is most frequently the transference of a methyl group to the 5-carbon position of the cytosine in a CpG dinucleotide, is one of the major mechanisms of epigenetic modifications. This modification plays an important role in gene expression, chromosomal stability, genomic imprinting, $\mathrm{X}$-chromosome inactivation, and mammalian development $[5,6]$. Recent genome-wide methylome studies have revealed sex-biased DNA methylation in specific

\footnotetext{
* Correspondence: shu-numata@umin.ac.jp

${ }^{1}$ Department of Psychiatry, Institute of Biomedical Sciences, Tokushima

University Graduate School, 3-18-15, Kuramoto, Tokushima 770-8503, Japan

Full list of author information is available at the end of the article
}

genes on the autosomes of several tissues, such as the blood, brain, and saliva [7-9, 4]. However, researchers have not yet investigated the sex differences in DNA methylation by taking into account cellular heterogeneity, although several studies have demonstrated the effects of cellular heterogeneity on DNA methylation status [10-16], and cell-type proportions may vary by sex.

To reveal sex differences in DNA methylation in human blood, we conducted a genome-wide profiling of DNA methylation by using peripheral leukocytes and then examined sex-biased DNA methylation after correcting the estimated cell-type proportions of each sample.
() Biomed Central (c) 2015 Inoshita et al. This is an Open Access article distributed under the terms of the Creative Commons Attribution License (http://creativecommons.org/licenses/by/4.0), which permits unrestricted use, distribution, and reproduction in any medium, provided the original work is properly credited. The Creative Commons Public Domain Dedication waiver (http:// creativecommons.org/publicdomain/zero/1.0/) applies to the data made available in this article, unless otherwise stated. 


\section{Methods \\ Subjects}

Ninety-three healthy subjects (49 males and 44 females; mean age: $43.6 \pm 12.3$ years) for our discovery set and 24 healthy subjects (14 males and 10 females, mean age: $35.3 \pm 11.9$ years) for our replication set were recruited from volunteers who comprised hospital staff, university students, and company employees. There was no significant age difference between male and female groups in both sample sets $(p>0.05)$. All subjects who joined this study were of unrelated Japanese origin and signed written informed consent forms that were approved by the institutional ethics committees of Tokushima University Graduate School and the Osaka University Graduate School of Medicine.

\section{DNA methylation methods}

Genomic DNA was prepared from peripheral blood samples. A bisulfite conversion of $500 \mathrm{ng}$ of genomic DNA was performed with the EZ DNA methylation kit (Zymo Research). DNA methylation levels were assessed with Infinium HumanMethylation450 BeadChips (Illumina Inc.) according to the manufacturer's instructions. This array's technical schemes, accuracy, and high reproducibility have been described in previous papers [17-19]. Quantitative measurements of DNA methylation were determined for 485,764 CpG dinucleotides that covered $99 \%$ of the RefSeq genes and were distributed across whole gene regions, including promoters, gene bodies, and 3'-untranslated regions (UTRs). The arrays also covered $96 \%$ of the CpG islands (CGIs) from the UCSC database with additional coverage in CGI shores $(0-2 \mathrm{~kb}$ from CGI) and CGI shelves (2-4 kb from CGI). DNA methylation data were analyzed using the methylation analysis module within the BeadStudio software (Illumina Inc.). The DNA methylation status of the CpG sites was calculated as the ratio of the signal from a methylated probe relative to the sum of both the methylated and unmethylated probes. This value, known as $\beta$, ranges from 0 (completely unmethylated) to 1 (fully methylated). For intra-chip normalization of the probe intensities, we performed color balance and background corrections on every set of 12 samples from the same chip by using internal control probes. For quality control, $\beta$ values with detection $p$ values $\geq 0.05$ were treated as missing values. Qualified CpG sites used in statistical analyses were defined as follows: 1) autosomal CpGs with no missing values in all subjects; 2) CpGs with no probe single nucleotide polymorphism (SNPs) at minor allele frequencies $\geq 5 \%$ in the HapMap-JPT population; 3) CpGs with no probe crossreactivity, and no SNPs at CpG sites and single-base extension sites in a previous paper [20]. The final data set included 345,235 CpG sites (promoter: 152,298; gene body: 104,707; 3'-UTR: 10,306; intergenic region: 77,924;
CpG island: 117,528; CpG island shore; 84,341; CpG island shelf: 30,207; others: 113,159). We deposited genome-wide DNA methylation data to the Gene Expression Omnibus (GEO) of the National Center for Biotechnology Information under the accession number GSE67393.

\section{Statistical analysis}

The cell-type proportions (CD4 + T cell, CD8 + T cell, CD56 + NK cell, CD19 + B cell, CD14 + monocyte, and granulocyte) for each of the samples were estimated using a published algorithm [21, 22] implemented in an R-package "Minfi," as we had done in our previous study [15]. Surrogate variable analysis (SVA), which is a method for modeling the potential confounding factors that may or may not be known, including technical factors such as batch effects, can increase the biological accuracy and reproducibility of analyses in microarray studies $[23,24]$. We used SVA to identify the potential confounding factors in our microarray data as surrogate variables (SVs). Then, we examined the influences of sex on DNA methylation with a multiple linear regression analysis after adjusting for age, significant SVs (8 SVs in the first set and $6 \mathrm{SVs}$ in the replication set), and the estimated 6 cell-type proportions, as in a previous study [8]. Bonferroni correction was applied at the 0.05 level for multiple testing (nominal $p$ value of $1.44 \times 10^{-7}$ ). The gene-ontology analysis was performed with the Database for Annotation, Visualization and Integrated Discovery (DAVID) [25].

\section{Results}

\section{Estimated cell-type proportions between males and} females

We estimated 6 cell-type proportions using "Minfi", a flexible and comprehensive bioconductor package for the analysis of Infinium DNA methylation microarrays developed by Aryee et al. [21]. The average estimated cellular proportions of the male and female groups are shown in Fig. 1. Of the 6 cell types, 2 (CD8 + T cell and CD56 + NK cell) showed small but significant differences between the two groups (Welch's $t$ test $p<0.05$ ), which could be confounding factors in determining sex-differential DNA methylation sites.

\section{Sex differences in DNA methylation in the blood}

The DNA methylation levels of 93 subjects were evaluated using Infinium HumanMethylation450 BeadChips, and then the sex differences of these levels between 49 males and 44 females were assessed using a multiple linear regression analysis after adjusting for age, the estimated cell-type proportions, and the SVs identified in our SVA. Of the 345,235 CpG sites, significant sex differences in DNA methylation were observed at $292 \mathrm{CpG}$ sites (nominal $p<1.44 \times 10^{-7}$, 


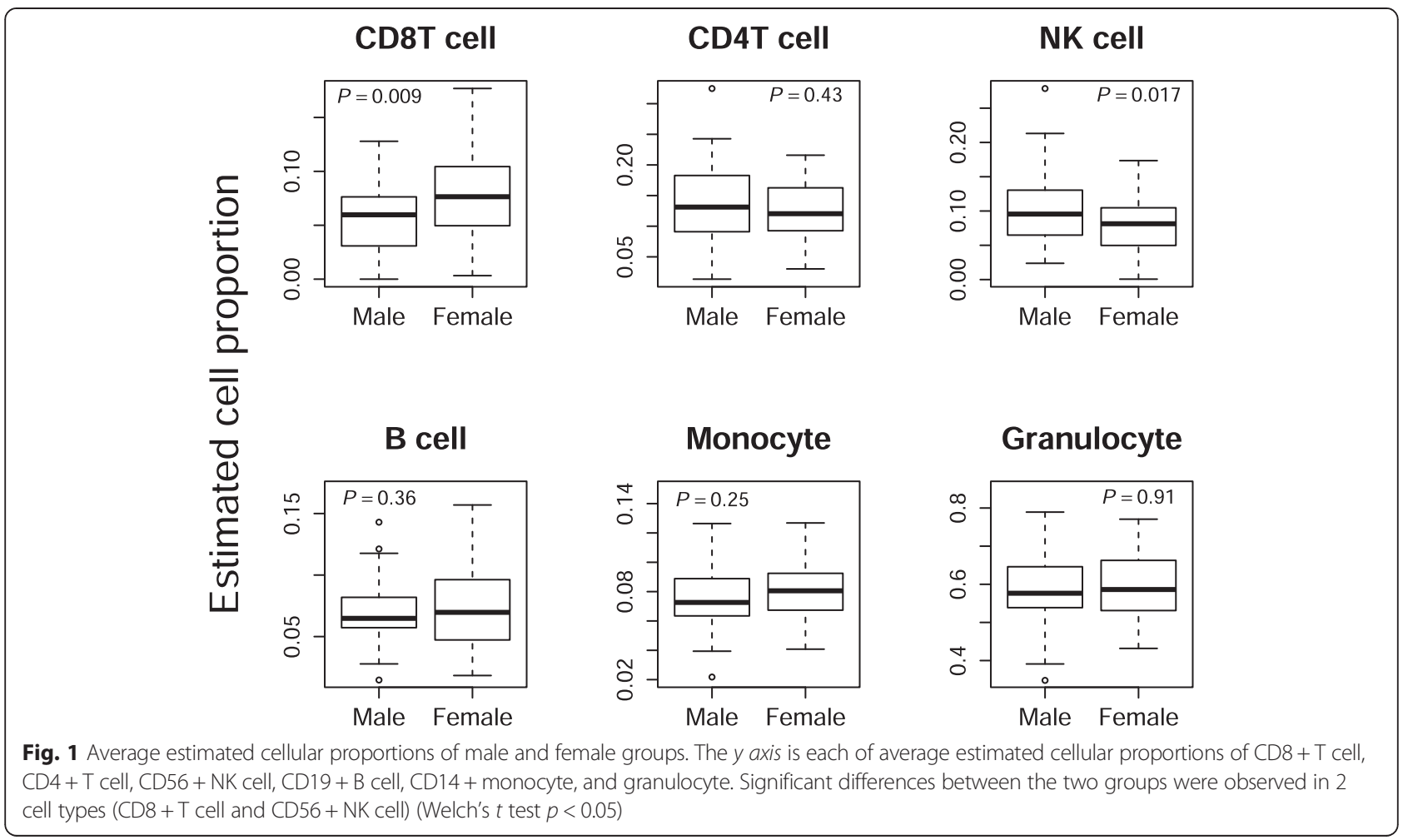

Additional file 1). When we analyzed array data without adjusting for the estimated cell-type proportions, significant sex differences were observed at 417 CpG sites (Additional file 2), and 270 sites were common between the results from the adjusted and un-adjusted analyses. The reduction in differentially methylated sites after cell proportion adjustment suggests that the present statistical analysis has the ability to lower false-positive detections of sexdifferential DNA methylation sites. Figure 2 shows volcano plots of differentially methylated CpG sites between males and females. Figure 3 shows a quantile-quantile (Q-Q) plot of $-\log _{10} \mathrm{P}$ values, which deviates from their expected values under the null hypothesis. Of the 292 CpG sites, 237 sites (81.2 \%) showed higher methylation in females than in males. Table 1 lists the top $20 \mathrm{CpG}$ sites that showed significant sex differences. When these $292 \mathrm{CpG}$ sites were classified into 4 different categories according to their locations in the genes (promoter, gene body, 3'-UTR, and intergenic region), 139 sites (47.6\%) were located in the promoter regions, 59 sites $(20.2 \%)$ in gene bodies, and 2 sites $(0.7 \%)$ in $3^{\prime}$-UTRs. When these 292 CpG sites were classified into 4 categories according to the CpG content in the genes (CGI, CGI shore, CGI shelf, and others), 139 sites (47.6 \%) were located in the CGIs, 10 sites (3.4\%) in CGI shores, and 76 sites $(26 \%)$ in CGI shelves.

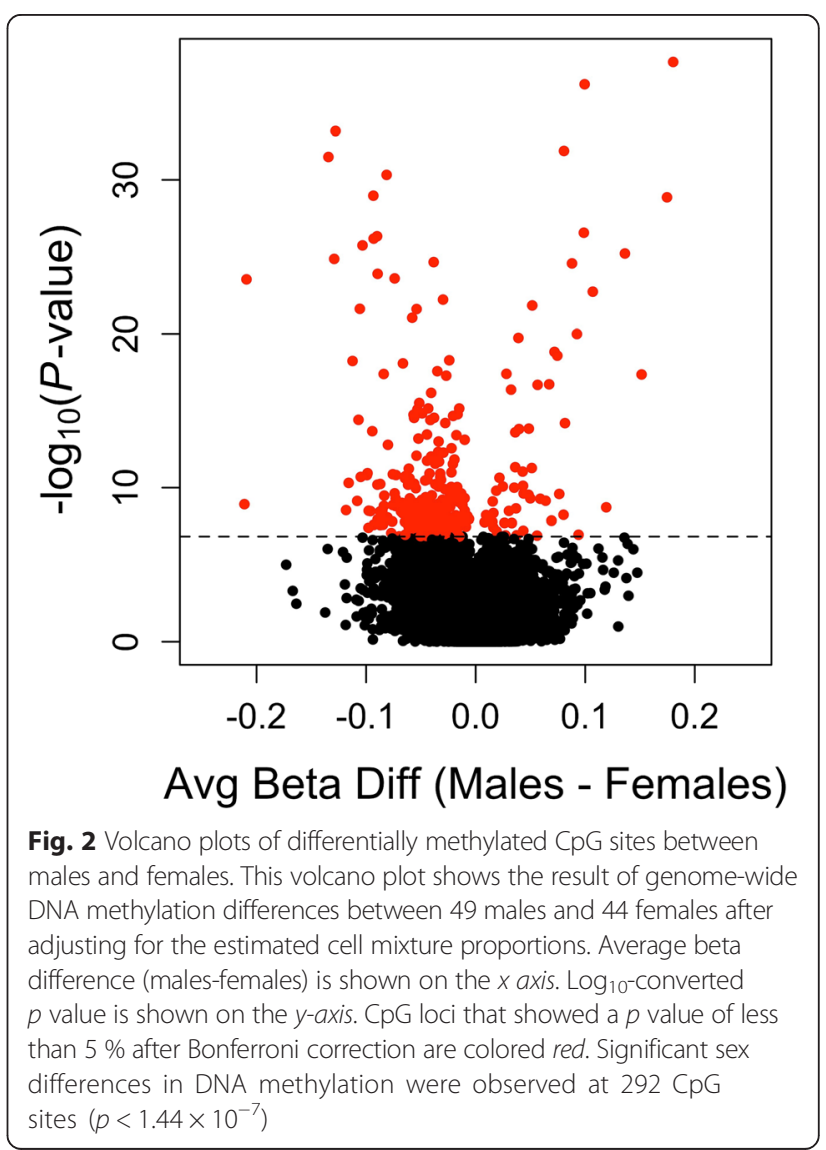




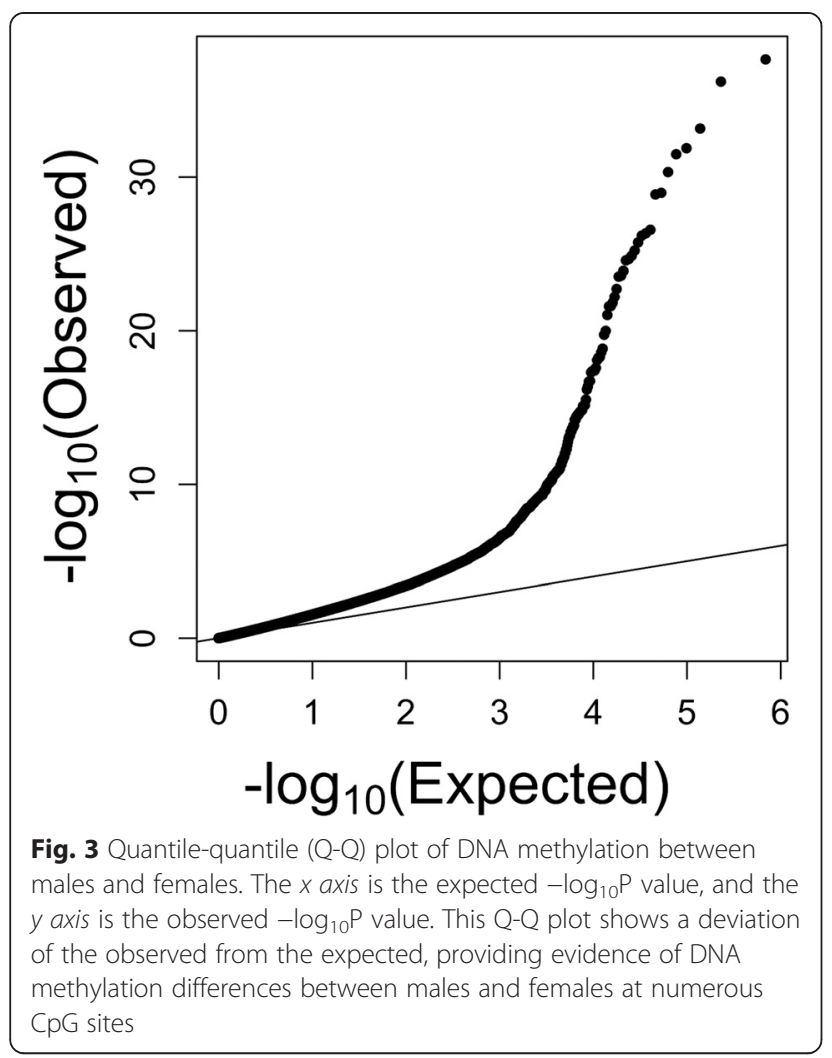

\section{Gene-ontology analysis}

We used DAVID to perform a gene-ontology analysis of the genes, which showed significant sex differences in DNA methylation, and revealed enrichment of genes related to secretion and secretion by cell. Table 2 lists the significant gene-ontology categories.

\section{Validation of sex differences in an independent set of samples}

DNA methylation levels were measured in an independent cohort of 14 males and 10 females using the same Illumina DNA methylation arrays. Of the top 20 differentially methylated $\mathrm{CpG}$ sites between males and females in the first set, the same directions (male > female or male $<$ female) were observed at all CpG sites, and significant sex differences were also observed at 16 sites in the replication set $(p<0.05)$ (Table 1). Of the 292 differentially methylated CpG sites in the first set, significant sex differences were also observed at 98 sites in the replication set $(p<0.05)$.

\section{Discussion}

In this study, we conducted a genome-wide DNA methylation profiling of the peripheral leukocytes from non-psychiatric subjects using Infinium HumanMethylation450 BeadChips and identified sex-biased genes on autosomes by adjusting for the estimated cell-type proportions. This blood study is the first to reveal sex differences in DNA methylation by taking into account cellular heterogeneity of blood in the analysis.

We revealed that most of significant loci $(81.2 \%)$ showed higher DNA methylation in females than in males. This finding is consistent with the results of previous studies [4, 7-9]. However, the explanation for this phenomenon is unclear. Gene-ontology analysis of biological process revealed that genes with sex differences in DNA methylation on autosomes were related to secretion and secretion by cell. Of these 8 secretionrelated genes, 5 genes (FKBP1B, SCIN, SMPD3, STEAP2, and TRIM36) has been associated with prostate cancer and hyperplasia [26-30]. These results may suggest some hormone-related genes are sex-differentially regulated, perhaps via methylation.

To date, two genome-wide methylome studies have examined sex-biased DNA methylation using Illumina Infinium HumanMethylation450 BeadChips [4, 9]. When we compared with the 614 sex-biased differential CpG sites on autosomes identified in a previous study using the human prefrontal cortex tissues [4], these $\mathrm{CPG}$ sites identified by $\mathrm{Xu}$ et al. were significantly enriched for those sites identified in the present study (common CpG site: 93 vs. 293, un-common CpG site: 521 vs. 344,942 , odds ratio $(\mathrm{OR})=210 ; 95 \%$ confidence intervals (CIs), 163-269; Fisher exact test $p<0.05)$. When we compared with the top 20 sexbiased differential CpG sites on autosomes in the study of $\mathrm{Xu}$ et al. [4], we observed common sexbiased DNA methylation at $17 \mathrm{CpG}$ sites which covered 14 distinctive genes (ARID1B, C6orf108, GLUD1, H3F3A, KRT77, SCIN, TFDP1, WBP11P1, YARS2, and ZNF69) in our blood study. These results suggest that sex-biased DNA methylation on autosomes in the brain is also observed in peripheral blood in specific genes, although tissue-specific differences in DNA methylation have been reported [31, 32]. ARID1B, which is a member of the SWI/SNF-A chromatin remodeling complex, has been implicated in intellectual disability and autism spectrum disorders [33, 34]. GLUD1, which plays a role at glutamatergic synapses [35], has been implicated in schizophrenia [36]. H3F3A, which encodes the replication-independent histone 3 variant $\mathrm{H} 3.3$, has been implicated in glioblastoma $[37,38]$.

When we compared with the 564 sex-biased differential genes on autosomes identified in a previous study using the human blood mononuclear cells from a high-aged cohort (over 95 years old) [9], we observed common sex-biased DNA methylation in only 15 genes (AGAP11, ANKRD11, C15orf29, HOXC4, HOXC5, HOXC6, MACROD1, NOTCH4, NSD1, OSTalpha, PEX10, PTPRN2, 
Table 1 Top 20 autosomal CpG sites with significant sex differences

\begin{tabular}{|c|c|c|c|c|c|c|c|c|c|c|c|c|c|}
\hline \multirow[b]{2}{*}{ Target ID } & \multirow[b]{2}{*}{$\begin{array}{l}\text { UCSC } \\
\text { RefGene } \\
\text { name }\end{array}$} & \multirow[b]{2}{*}{ Chromosome } & \multirow[b]{2}{*}{ Position $^{a}$} & \multirow[b]{2}{*}{$\begin{array}{l}\text { Relation } \\
\text { to UCSC } \\
\text { CpG island }\end{array}$} & \multirow[b]{2}{*}{$\begin{array}{l}\text { UCSC } \\
\text { RefGene } \\
\text { group }\end{array}$} & \multicolumn{4}{|l|}{ First set } & \multicolumn{4}{|c|}{ Second set } \\
\hline & & & & & & $\begin{array}{l}\text { Mean } \beta \\
\text { value of } \\
\text { male }\end{array}$ & $\begin{array}{l}\text { Mean } \beta \\
\text { value of } \\
\text { female }\end{array}$ & $\begin{array}{l}\text { Sex average } \\
\text { difference } \\
\text { of } \beta \text { value }\end{array}$ & $\overline{\text { Sexp value }}$ & $\begin{array}{l}\text { Mean } \\
\beta \text { value } \\
\text { of male }\end{array}$ & $\begin{array}{l}\text { Mean } \\
\beta \text { value } \\
\text { of female }\end{array}$ & $\begin{array}{l}\text { Sex average } \\
\text { difference } \\
\text { of } \beta \text { value }\end{array}$ & $\overline{\text { Sex } p \text { value }}$ \\
\hline $\operatorname{cg} 12691488$ & & 1 & $2.4 E+08$ & CGI & Intergenic & 0.352 & 0.171 & 0.180 & $2.26 \mathrm{E}-38$ & 0.263 & 0.111 & 0.152 & $2.11 \mathrm{E}-03$ \\
\hline cg03618918 & & 1 & $1.6 \mathrm{E}+08$ & Others & Intergenic & 0.790 & 0.691 & 0.099 & $6.38 \mathrm{E}-37$ & 0.825 & 0.745 & 0.079 & 3.04E-03 \\
\hline cg17238319 & RFTN1 & 3 & $1.6 \mathrm{E}+07$ & Others & Gene body & 0.660 & 0.788 & -0.128 & $6.88 \mathrm{E}-34$ & 0.703 & 0.816 & -0.113 & 5.19E-02 \\
\hline cg25304146 & WBP11P1 & 18 & $3 E+07$ & Others & Gene body & 0.630 & 0.550 & 0.081 & $1.31 \mathrm{E}-32$ & 0.704 & 0.604 & 0.100 & $5.78 \mathrm{E}-02$ \\
\hline cg03691818 & KRT77 & 12 & $5.3 \mathrm{E}+07$ & Others & Gene body & 0.043 & 0.178 & -0.134 & $3.25 \mathrm{E}-32$ & 0.052 & 0.254 & -0.202 & 7.13E-04 \\
\hline $\operatorname{cg} 17232883$ & & 11 & $5.9 E+07$ & Others & Intergenic & 0.076 & 0.157 & -0.081 & $4.72 \mathrm{E}-31$ & 0.056 & 0.123 & -0.067 & $1.42 \mathrm{E}-04$ \\
\hline cg25568337 & ARID1B & 6 & $1.6 \mathrm{E}+08$ & Others & Promoter & 0.164 & 0.258 & -0.093 & $1.07 E-29$ & 0.152 & 0.297 & -0.145 & 1.15E-04 \\
\hline cg04946709 & LOC644649 & 16 & $6 \mathrm{E}+07$ & CGl & Gene body & 0.805 & 0.631 & 0.175 & $1.37 \mathrm{E}-29$ & 0.823 & 0.499 & 0.324 & 8.79E-05 \\
\hline cg22266749 & COL25A1 & 4 & $1.1 \mathrm{E}+08$ & CGI & Promoter & 0.192 & 0.093 & 0.099 & $2.77 \mathrm{E}-27$ & 0.229 & 0.107 & 0.122 & $1.52 \mathrm{E}-02$ \\
\hline $\operatorname{cg} 12177922$ & HAX1 & 1 & $1.5 \mathrm{E}+08$ & CGl & Promoter & 0.207 & 0.297 & -0.090 & $4.68 \mathrm{E}-27$ & 0.161 & 0.236 & -0.074 & $3.68 \mathrm{E}-02$ \\
\hline cg23719534 & & 15 & $1 \mathrm{E}+08$ & CGl & Intergenic & 0.859 & 0.952 & -0.093 & $6.67 E-27$ & 0.858 & 0.949 & -0.091 & 3.87E-03 \\
\hline cg20299935 & & 17 & $2.2 \mathrm{E}+07$ & Others & Intergenic & 0.708 & 0.811 & -0.103 & $1.84 \mathrm{E}-26$ & 0.740 & 0.813 & -0.073 & 8.56E-01 \\
\hline cg12052203 & B3GNT1 & 11 & $6.6 \mathrm{E}+07$ & CGI & Promoter & 0.172 & 0.035 & 0.136 & $6.19 \mathrm{E}-26$ & 0.210 & 0.050 & 0.160 & $1.23 \mathrm{E}-03$ \\
\hline cg06710937 & & 13 & $2.3 \mathrm{E}+07$ & CGI & Intergenic & 0.062 & 0.191 & -0.129 & $1.39 \mathrm{E}-25$ & 0.036 & 0.173 & -0.137 & $5.72 \mathrm{E}-04$ \\
\hline cg23814743 & NICN1 & 3 & $4.9 \mathrm{E}+07$ & CGl & Promoter & 0.239 & 0.277 & -0.038 & $2.25 \mathrm{E}-25$ & 0.121 & 0.158 & -0.038 & $1.81 \mathrm{E}-03$ \\
\hline cg15817705 & & 1 & $2.1 \mathrm{E}+08$ & CGI shore & Intergenic & 0.750 & 0.662 & 0.088 & 2.73E-25 & 0.759 & 0.683 & 0.076 & 3.01E-02 \\
\hline cg03218192 & AP2B1 & 17 & $3.4 \mathrm{E}+07$ & Others & Promoter & 0.276 & 0.365 & -0.089 & $1.30 \mathrm{E}-24$ & 0.228 & 0.344 & -0.116 & $2.43 \mathrm{E}-03$ \\
\hline cg07852945 & TLE1 & 9 & $8.4 E+07$ & CGl & Promoter & 0.103 & 0.177 & -0.074 & $2.58 \mathrm{E}-24$ & 0.047 & 0.137 & -0.090 & $1.83 \mathrm{E}-04$ \\
\hline cg23256579 & PRR4 & 12 & $1.1 \mathrm{E}+07$ & Others & Promoter & 0.422 & 0.631 & -0.209 & 2.97E-24 & 0.363 & 0.573 & -0.210 & 4.33E-03 \\
\hline cg25294185 & RNASEH2C & 11 & $6.5 \mathrm{E}+07$ & CGl & Gene body & 0.171 & 0.064 & 0.107 & $1.88 \mathrm{E}-23$ & 0.162 & 0.086 & 0.076 & $6.48 \mathrm{E}-01$ \\
\hline
\end{tabular}

apositions refer to Genome Research Consortium human genome build 37 (GRCh37)/UCSC human genome 19 (hg19) 
Table 2 Gene-ontology analysis of the genes which showed significant sex differences in DNA methylation in this study $(p<0.01)$

\begin{tabular}{lllll}
\hline Category & Term & Gene count (\%) & $p$ value & Fold enrichment \\
\hline GOTERM_CC_FAT & GO:0031965 nuclear membrane & $5(3.36)$ & 2.49. E-03 & 8.70 \\
GOTERM_CC_FAT & GO:0031301 integral to organelle membrane & $6(4.03)$ & 2.74. E- 03 & 6.17 \\
GOTERM_CC_FAT & GO:0012505 endomembrane system & $15(10.07)$ & 2.84 E-03 & 2.43 \\
GOTERM_CC_FAT & GO:0005635 nuclear envelope & $7(4.70)$ & $5.42 . E-03$ & 4.31 \\
GOTERM_BP_FAT & GO:0032940 secretion by cell & $7(4.70)$ & 5.85. E-03 & 4.25 \\
GOTERM_CC_FAT & GO:0031300 intrinsic to organelle membrane & $6(4.03)$ & $5.96 . E-03$ & 5.14 \\
GOTERM_BP_FAT & GO:0046903 secretion & $8(5.37)$ & 9.30. E-03 & 3.36 \\
\hline
\end{tabular}

SHANK3, TFDP1, and UNC84A) in our study. This difference between studies might be due to the large difference in subjects' mean age and the fact that Sun et al. did not correct for sex-differential cell-type proportions. Both age and cell-type proportion are well known to be major confounding factors in DNA methylation $[12,16]$. However, sex-biased genes identified by Sun et al. were significantly enriched for those genes identified in the present study (common gene: 15 vs. 193, un-common gene: 549 vs. 19,533, $\mathrm{OR}=2.8$; $95 \% \mathrm{CI}, 1.5-4.7$; Fisher exact test $p<0.05)$. Mai and colleagues (2010) has demonstrated HoxC4mediated regulation of activation-induced cytosine deaminase expression, as enhanced by estrogen, and has suggested a possible role of this homeodomain transcription factor in mediating immunopotentiation in gestation and neonatal and adult life [39].

There are several limitations to the present study. First, our sample size was not large. Replication studies with larger samples will be needed. Second, the cellular proportions were created by a bioinformatics tool, so these were not based on direct observation of the relative numbers of cells in the sample. Furthermore, experimental noises may be increased due to the circular use of DNA methylation data, as these data are used first to define cell-type proportions, which are then used as covariates in the differential methylation analysis. Cell-type-specific studies will be needed. Third, we did not take other confounding factors, such as smoking or body mass index, into consideration in our analysis, which may affect DNA methylation status $[40,41]$, because these information were not collected in the present study.

\section{Conclusions}

In summary, we identified sex-biased DNA methylation at numerous CPG sites on autosomes by conducting a comprehensive DNA methylation profiling of blood and by adjusting for estimated cellular proportions. These findings provided further evidence that DNA methylation may play a role in the differentiation or maintenance of sexual dimorphisms, and our methylome mapping of the effects of sex may be useful to understanding the molecular mechanism involved in normal development and diseases.

\section{Additional files}

Additional file 1: 292 CpG sites which showed significant gender differences in DNA methylation at $5 \%$ Bonferroni correction.

Additional file 2: $417 \mathrm{CpG}$ sites which showed significant gender differences in DNA methylation at $5 \%$ Bonferroni correction.

\section{Abbreviations}

CGIs: CpG islands; DAVID: Database for Annotation, Visualization and Integrated Discovery; SNPs: single nucleotide polymorphism; SVA: surrogate variable analysis; SVs: surrogate variables; UTRs: 3'-untranslated regions.

\section{Competing interests}

This work was supported in part by the Japan Science and Technology Agency, CREST, and a Grant-in-Aid for Scientific Research from the Japanese Ministry of Education, Culture, Sports, Science and Technology (grant number 24791216), SENSHIN Medical Research Foundation, and the Research Group for Schizophrenia. The authors have no conflicts to disclose.

\section{Author's contributions}

NS designed the study. NS and OT managed the research. NS, YH, and HR collected the samples. IM, KM, and NS performed the experiments. II, KM, TA, and $\mathrm{UH}$ undertook the statistical analysis. IM wrote the first draft of this paper. All authors read and approved the final manuscript.

\section{Acknowledgements}

The authors would like to thank Mrs. Akemi Okada for her technical assistance. The authors would also like to give their gratitude to all of the volunteers who understood the purpose of our study and participated in this study.

\section{Author details}

${ }^{1}$ Department of Psychiatry, Institute of Biomedical Sciences, Tokushima University Graduate School, 3-18-15, Kuramoto, Tokushima 770-8503, Japan. ${ }^{2}$ Department of Human Genetics, Institute of Biomedical Sciences, Tokushima University Graduate School, 3-18-15, Kuramoto, Tokushima 770-8503, Japan. ${ }^{3}$ Department of Bioinformatics and Genomics, Graduate School of Medical Sciences, Kanazawa University, 13-1, Takaramachi, Kanazawa, Ishikawa

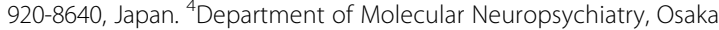
University Graduate School of Medicine, Suita Osaka 5650871, Japan. ${ }^{5}$ Department of Psychiatry, Osaka University Graduate School of Medicine, Suita, Osaka 5650871, Japan. ${ }^{6}$ Molecular Research Center for Children's Mental Development, United Graduate School of Child Development, Osaka University, Suita, Osaka 5650871, Japan. 
Received: 26 November 2014 Accepted: 6 June 2015

Published online: 25 June 2015

\section{References}

1. Morgan CP, Bale TL. Sex differences in microRNA regulation of gene expression: no smoke, just miRs. Biol Sex Differ. 2012;3(1):22

2. Vawter MP, Evans S, Choudary P, Tomita H, Meador-Woodruff J, Molnar M, et al. Gender-specific gene expression in post-mortem human brain: localization to sex chromosomes. Neuropsychopharmacology. 2004;29(2):373-84.

3. Weickert CS, Elashoff M, Richards AB, Sinclair D, Bahn S, Paabo S, et al. Transcriptome analysis of male-female differences in prefrontal cortical development. Mol Psychiatry. 2009;14(6):558-61.

4. $\mathrm{Xu} \mathrm{H}$, Wang F, Liu Y, Yu Y, Gelernter J, Zhang H. Sex-biased methylome and transcriptome in human prefrontal cortex. Hum Mol Genet. 2014;23(5):1260-70.

5. Gut $P$, Verdin $E$. The nexus of chromatin regulation and intermediary metabolism. Nature. 2013;502(7472):489-98.

6. Reik W. Stability and flexibility of epigenetic gene regulation in mammalian development. Nature. 2007:447(7143):425-32.

7. Liu J, Morgan M, Hutchison K, Calhoun VD. A study of the influence of sex on genome wide methylation. PLoS One. 2010;5(4), e10028.

8. Numata S, Ye T, Hyde TM, Guitart-Navarro X, Tao R, Wininger M, et al. DNA methylation signatures in development and aging of the human prefrontal cortex. Am J Hum Genet. 2012;90(2):260-72.

9. Sun L, Lin J, Du H, Hu C, Huang Z, Lv Z, et al. Gender-specific DNA methylome analysis of a Han Chinese longevity population. Biomed Res Int. 2014;2014:396727

10. Adalsteinsson BT, Gudnason H, Aspelund T, Harris TB, Launer LJ, Eiriksdottir G, et al. Heterogeneity in white blood cells has potential to confound DNA methylation measurements. PLoS One. 2012;7(10), e46705.

11. Guintivano J, Aryee MJ, Kaminsky ZA. A cell epigenotype specific model for the correction of brain cellular heterogeneity bias and its application to age, brain region and major depression. Epigenetics. 2013;8(3):290-302.

12. Jaffe $A E$, Irizarry RA. Accounting for cellular heterogeneity is critical in epigenome-wide association studies. Genome Biol. 2014;15(2):R31.

13. Lam LL, Emberly E, Fraser HB, Neumann SM, Chen E, Miller GE, et al. Factors underlying variable DNA methylation in a human community cohort. Proc Natl Acad Sci U S A. 2012;16:109.

14. Liu Y, Aryee MJ, Padyukov L, Fallin MD, Hesselberg E, Runarsson A, et al. Epigenome-wide association data implicate DNA methylation as an intermediary of genetic risk in rheumatoid arthritis. Nat Biothechnol. 2013;31(2):142-7.

15. Kinoshita M, Numata S, Tajima A, Ohi K, Hashimoto R, Shimodera S, et al. Aberrant DNA methylation of blood in schizophrenia by adjusting for estimated cellular proportions. Neuromolecular Med 2014, [Epub ahead of print].

16. Reinius LE, Acevedo N, Joerink M, Pershagen G, Dahlén SE, Greco D, et al. Differential DNA methylation in purified human blood cells: implications for cell lineage and studies on disease susceptibility. PLoS One. 2012;7(7), e41361.

17. Bibikova M, Barnes B, Tsan C, Ho V, Klotzle B, Le JM, et al. High density DNA methylation array with single CpG site resolution. Genomics. 2011;98(4):288-95.

18. Dedeurwaerder S, Defrance M, Calonne E, Denis H, Sotiriou C, Fuks F. Evaluation of the Infinium Methylation 450K technology. Epigenomics. 2011;3(6):771-84

19. Sandoval J, Heyn H, Moran S, Serra-Musach J, Pujana MA, Bibikova M, et al. Validation of a DNA methylation microarray for 450,000 CpG sites in the human genome. Epigenetics. 2011;6(6):692-702.

20. Chen YA, Lemire M, Choufani S, Butcher DT, Grafodatskaya D, Zanke BW, et al. Discovery of cross-reactive probes and polymorphic CpGs in the Illumina Infinium HumanMethylation450 microarray. Epigenetics. 2013;8(2):203-9.

21. Aryee MJ, Jaffe AE, Corrada-Bravo H, Ladd-Acosta C, Feinberg AP, Hansen KD, et al. Minfi: a flexible and comprehensive bioconductor package for the analysis of Infinium DNA methylation microarrays. Bioinformatics. 2014;30(10):1363-9.

22. Houseman EA, Molitor J, Marsit CJ. Reference-free cell mixture adjustments in analysis of DNA methylation data. Bioinformatics. 2014;30(10):1431-9.

23. Leek JT, Storey JD. Capturing heterogeneity in gene expression studies by surrogate variable analysis. PLoS Genet. 2007;3(9):1724-35.
24. Teschendorff AE, Zhuang J, Widschwendter M. Independent surrogate variable analysis to deconvolve confounding factors in large-scale microarray profiling studies. Bioinformatics. 2011;27(11):1496-505.

25. da Huang W, Sherman BT, Lempicki RA. Systematic and integrative analysis of large gene lists using DAVID bioinformatics resources. Nat Protoc. 2009;4(1):44-57.

26. Gallardo-Arrieta F, Doll A, Rigau M, Mogas T, Juanpere N, García F, et al. A transcriptional signature associated with the onset of benign prostate hyperplasia in a canine model. Prostate. 2010;70(13):1402-12.

27. Wang D, Sun SQ, Yu YH, Wu WZ, Yang SL, Tan JM. Suppression of SCIN inhibits human prostate cancer cell proliferation and induces G0/G1 phase arrest. Int J Oncol. 2014;44(1):161-6.

28. Schulze J, Albers J, Baranowsky A, Keller J, Spiro A, Streichert T, et al. Osteolytic prostate cancer cells induce the expression of specific cytokines in bone-forming osteoblasts through a Stat3/5-dependent mechanism. Bone. 2010;46(2):524-33.

29. Ihlaseh-Catalano SM, Drigo SA, de Jesus CM, Domingues MA, Trindade Filho JC, de Camargo $\mathrm{L} L$, et al. STEAP1 protein overexpression is an independent marker for biochemical recurrence in prostate carcinoma. Histopathology. 2013;63(5):678-85.

30. Fujimura T, Takahashi S, Urano T, Takayama K, Sugihara T, Obinata D, et al. Expression of androgen and estrogen signaling components and stem cell markers to predict cancer progression and cancer-specific survival in patients with metastatic prostate cancer. Clin Cancer Res. 2014;20(17):4625-35.

31. Christensen BC, Houseman EA, Marsit CJ, Zheng S, Wrensch MR, Wiemels $\mathrm{J}$, et al. Aging and environmental exposures alter tissue-specific DNA methylation dependent upon CpG island context. PLoS Genet. 2009:5(8), e1000602.

32. Davies MN, Volta M, Pidsley R, Lunnon K, Dixit A, Lovestone S, et al. Functional annotation of the human brain methylome identifies tissue-specific epigenetic variation across brain and blood. Genome Biol. 2012;13(6):R43

33. Hoyer J, Ekici AB, Endele S, Popp B, Zweier C, Wiesener A, et al. Haploinsufficiency of ARID1B, a member of the SWI/SNF-a chromatinremodeling complex, is a frequent cause of intellectual disability. Am J Hum Genet. 2012;90(3):565-72

34. Halgren C, Kjaergaard S, Bak M, Hansen C, El-Schich Z, Anderson CM, et al. Corpus callosum abnormalities, intellectual disability, speech impairment, and autism in patients with haploinsufficiency of ARID1B. Clin Genet. 2012;82(3):248-55.

35. Hepp R, Hay YA, Aguado C, Lujan R, Dauphinot L, Potier MC, et al. Glutamate receptors of the delta family are widely expressed in the adult brain. Brain Struct Funct 2014, Jul 8 [Epub ahead of print].

36. Jia P, Wang L, Meltzer HY, Zhao Z. Common variants conferring risk of schizophrenia: a pathway analysis of GWAS data. Schizophr Res. 2010;122(1-3):38-42.

37. Schwartzentruber J, Korshunov A, Liu XY, Jones DT, Pfaff E, Jacob K, et al. Driver mutations in histone $\mathrm{H} 3.3$ and chromatin remodelling genes in paediatric glioblastoma. Nature. 2012;482(7384):226-31.

38. Sturm D, Witt H, Hovestadt V, Khuong-Quang DA, Jones DT, Konermann C, et al. Hotspot mutations in $\mathrm{H3F} 3 \mathrm{~A}$ and IDH1 define distinct epigenetic and biological subgroups of glioblastoma. Cancer Cell. 2012;22(4):425-37.

39. Mai T, Zan H, Zhang J, Hawkins JS, Xu Z, Casali P. Estrogen receptors bind to and activate the HOXC4/HoxC4 promoter to potentiate HoxC4-mediated activation-induced cytosine deaminase induction, immunoglobulin class switch DNA recombination, and somatic hypermutation. J Biol Chem. 2010;285(48):37797-810.

40. Breitling LP, Yang R, Korn B, Burwinkel B, Brenner H. Tobacco-smokingrelated differential DNA methylation: $27 \mathrm{~K}$ discovery and replication. Am J Hum Genet. 2011;88(4):450-7.

41. Dick KJ, Nelson CP, Tsaprouni L, Sandling JK, Aïssi D, Wahl S, et al. DNA methylation and body-mass index: a genome-wide analysis. Lancet. 2014;S0140-6736(13):62674-4. 